\title{
In memory of Amnon Piepsz
}

\author{
Alain Prigent ${ }^{1,2}$ \\ Published online: 19 August 2021 \\ ๑ The Author(s), under exclusive licence to Springer-Verlag GmbH Germany, part of Springer Nature 2021
}

His name was Amnon Piepsz, but we called him Amy. This nickname (Amy in place of Amnon) prophesies his profound personality ("ami," in French, means friend!). Whatever the regarded matter of his life, either medicine, or music, or again day-to-day living, Amy had exceptionally high qualities, rarely found in one person.

Amy was born on November 14, 1938, in Antwerp (Belgium) and died on July 26 in Brussels (Belgium).

Postgraduate in pediatrics (1967), Amy became interested in nuclear medicine methodologies by its physiological and non-invasive approach. Becoming postgraduate in nuclear medicine (1969), he eventually was nominated professor both in pediatrics and in nuclear medicine at the Free University of Brussels.

His PhD thesis (1988) was entitled "Methodology of separate clearance measurement by means of ${ }^{99 \mathrm{~m}} \mathrm{Tc}$-DTPA and the gamma camera." Although he enlarged his clinical and research work in many other domains, more than 10 years later, he was still carrying with enthusiasm the progress of this issue and was a major contributor to the international consensus report on "the quality control of quantitative measurements of renal function obtained from the renogram," published by the International Scientific Committee of Radionuclides in Nephrourology (ISCORN).

His main fields of interest were directed toward the development of the methodology in children and adults especially about glomerular filtration rate measurements, split renal function estimation by camera, whatever the radiopharmaceutical used, and uronephrological problems in children (hydronephrosis, urinary tract infections, and reflux).

This article is part of the Topical Collection on Editorial.

$\triangle$ Alain Prigent

prigentalain@yahoo.fr

1 Nuclear Medicine Department, University Hospital of Bicêtre, Le Kremlin-Bicêtre, France

2 Biophysics and Nuclear Medicine, University Paris-Sud, Paris, France
In addition, Amy worked as a pediatrician in the general outpatient clinic with special interest in urinary tract infections, mother-child relationship, and psychosomatic diseases. He was an attentive clinician, a physician devoted to the children, their parents, and his department collaborators too, giving intimate relationship and support. He was a publishing prolific author of about one hundred articles, both in experimental and clinical domains, not only in nuclear medicine but in pediatrics and urology, too. In 2006, Amy co-edited the book entitled Functional Imaging in NephroUrology, under the auspices of ISCORN, bringing together the presentations of the more recent developments in the domain by an international and multidisciplinary group of physicians, surgeons, radiologists, and nuclear medicine specialists.

Most of Amy's career was spent at the "Centre Hospitalo-Universitaire-St Pierre" and in the Academic Hospital of the Free University (Brussels). After his official retirement, he continued to work as a volunteer in the University Hospital Ghent, where he has pursed his research and the education of trainees. He was an inspirational figure, easily available, supportive to novices in nuclear medicine, and attentive to explain and to associate newcomers with his scientific knowledge and clinical acumen to improve either their theoretical knowledge or their "day life know-how" with patients. As an example, with his chief nurse H. Pintelon, he organized congress presentations and publications about such an issue. Amy spread collaborations, support, and friendship throughout he passed by.

Member of the Societies of Nuclear Medicine and of Pediatrics of Belgium, Amy has been a very active member of the European Association of Nuclear Medicine (EANM) and the undisputed and beloved chairman and member of the Paediatric Task Group of the EANM, in which he had ongoing work for more than 20 years. He was a member of the International Scientific Committee of Radionuclides in Nephro-urology_-ISCORN—a refounded working group of "Radionuclides in nephro-urology," initiated by D. Blaufox about 20 years earlier. 
Amy was involved in two European study groups of EANM, the one about Captopril renography and the other one about reflux in children (IRSC).

He has been a very contributive editor of nuclear medicine journals (European Journal of Nuclear Medicine and Molecular Imaging, Nuclear Medicine Communications, Revista de Medicina Nuclear, Médecine Nucléaire, and World Journal of Nuclear Medicine) and a scientific reviewer of the Journal of Nuclear Medicine, the European Journal of Urology, and the Journal of Urology, in addition to the cited nuclear medicine journals.

Amy was a genuine world citizen, giving lectures and leading courses in Bombay, Cape Town, and Djakarta (International Atomic Energy Agency), and he was on the faculty of the European School of Nuclear Medicine (European Association of Nuclear Medicine and Paris University). Yearly, he taught uro-nephrology and pediatrics in nuclear medicine. Unfortunately, this English-given training only persisted 2 years because it received few supportive diffusion (thankfully, the equivalent course about "radiopharmaceuticals and radiopharmacy" lasted longer). Amy was enthusiastic about this initiative and would have been able to give his courses in any of the three languages initially agreed (English, German, and French) to complete this first settlement of the "European School" in France by two similar institutions in large European cities providing a kind of harmonized training program at the European level. Nevertheless, Amy worked to support the development of nuclear medicine in many countries (especially Chile). He spoke many foreign languages (five fluently and two others well) and liked to explore cities in many countries and to become familiar with the inhabitants, museums, and cultures.

He had qualities rarely seen in one person and was an inspirational figure, easily available, supportive to novices in nuclear medicine, and attentive to explain and to associate newcomers with his scientific knowledge and clinical acumen to improve their practice with patients. He was an attentive clinician, a physician devoted to the children, their parents, and his department collaborators too.

Although he exuded enthusiasm for nuclear medicine throughout his career, Amy's life out of the medicine was very rich too. Having experienced two tragic events early in his life (escaping Nazi extermination as a young child and suffering from his mother's death as an adolescent), Amy nevertheless bounced back, and leaving his passion and amazing gift to piano, he began a medical cursus.

His daring son, Olivier, has been taking care of him during Amy's decline, which began with a manual disturbance while playing piano. Indeed, Amy was an unbelievable pianist. When he was a 15-year-old, he received the First Prize of the Brussels conservatoire contest of piano! Two years later, he received a Steinway Prize! He was able to play with expertise and feeling a full range of classical music. Invited at his home in Brussels, you could pick up any partition from his wall, and Amy played it singing in low tone. After a successful congress day, he kindly accepted to interpret some classical compositions on the piano of the hotel to delight his friendly colleagues. When he was not singing in the European Union professional choir (President), he also used to play in duo with a friend violinist in some private concerts.

He was a lover and expert of art, sharing his enthusiasm and joy with others. He liked to swim, play tennis, and hike in mountains, often with his dear colleagues.

We will all miss him and remember him fondly as an irreplaceable friend.

\section{Declarations}

Ethics approval Institutional Review Board approval was not required because the paper is an Obituary.

Informed consent Not applicable.

Conflict of interest The author declares no competing interests.

Publisher's note Springer Nature remains neutral with regard to jurisdictional claims in published maps and institutional affiliations. 